\title{
Ultrasensitive and Selective Electrochemical Detection of Dopamine Based on CuO/PVA Nanocomposite-Modified GC Electrode
}

\author{
A. Mohamed Azharudeen $\left(D,{ }^{1}\right.$ Arpita Roy ${ }^{D},{ }^{2}$ R. Karthiga, ${ }^{3}$ S. Arun Prabhu, ${ }^{4}$ M. G. Prakash, \\ A. Mohamed Ismail Badhusha, ${ }^{6}$ Huma Ali, ${ }^{7}$ Khadijah Mohammedsaleh Katubi, ${ }^{8}$ \\ and Md. Rabiul Islam $\left.{ }^{9}\right)^{9}$ \\ ${ }^{1}$ Department of Chemistry, M.S.S. Wakf Board College, Madurai - 625020, India \\ ${ }^{2}$ Department of Biotechnology, School of Engineering \& Technology, Sharda University, Greater Noida 201310, India \\ ${ }^{3} P G$ \& Research Department of Chemistry, C.P.A. College, Bodinayakanur - 625513, India \\ ${ }^{4}$ Department of Chemistry, National College, Tiruchirappalli, Tamilnadu - 620001, India \\ ${ }^{5}$ Department of Chemistry, University of Witwatersrand, Johannesburg - 2050, South Africa \\ ${ }^{6}$ Research Department of Chemistry, Sadakathullah Appa College, Tirunelveli - 627011, India \\ ${ }^{7}$ Department of Chemistry, Maulana Azad National Institute of Technology Bhopal, India \\ ${ }^{8}$ Department of Chemistry, College of Science, Princess Nourah bint Abdulrahman University, P.O. Box 84428, \\ Riyadh 11671, Saudi Arabia \\ ${ }^{9}$ Department of Pharmacy, University of Asia Pacific, Dhaka, Bangladesh
}

Correspondence should be addressed to A. Mohamed Azharudeen; azhar5406@gmail.com, Arpita Roy; arbt2014@gmail.com, and Md. Rabiul Islam; robi.ayaan@gmail.com

Received 16 January 2022; Accepted 5 February 2022; Published 22 February 2022

Academic Editor: V. Mohanavel

Copyright (c) 2022 A. Mohamed Azharudeen et al. This is an open access article distributed under the Creative Commons Attribution License, which permits unrestricted use, distribution, and reproduction in any medium, provided the original work is properly cited.

At present, the determination of dopamine (DA) is enormously necessary for the human body. Since then, it has played a crucial role in the brain that affects mood, sleep, memory, learning, and concentration. Dopamine insufficiency is a threat to human health. Dopamine recognition is important to avoid this problem. Copper oxide $(\mathrm{CuO})$ nanoparticles are one of the potentials which can be used in the detection of dopamine level in the sample. In this work, $\mathrm{CuO}$ was synthesized by a simple chemical precipitation technique and modified by polyvinyl alcohol (PVA) as a capping agent. The nanomaterials manufactured are used for the detection of dopamine in $0.1 \mathrm{M}$ PBS medium at room temperature. The CuO/PVA-modified electrode shows better electrocatalytic activity than $\mathrm{CuO} / \mathrm{GCE}$ (glassy carbon electrode). The constructed dopamine biosensor of copper oxide-PVA nanocomposites also has extraordinary selectivity, stability, sensitivity $\left(183.12 \mu \mathrm{AmM}^{-1} \mathrm{~cm}^{-2}\right)$, and a minimum level detection limit of $0.017 \mu \mathrm{M}$, is inexpensive, and has minimal effort and rapid detection of dopamine.

\section{Introduction}

The biomolecules are playing a significant role in the human body. They are involved in metabolic processes, and some of them act as neurotransmitters, neuroactive molecules, etc. Among the biomolecules, dopamine is one of the predominated ones, which is located naturally in the human body.
It is a catecholamine neurotransmitter that directs the signal from the body to the brain. It controls the movement and emotional responses of humans. When dopamine levels are diminished in the human body, it causes Parkinson and schizophrenic diseases [1]. Furthermore, dopamine regulates all brain functions; it may protect the human heart racing and widen blood vessels in the viscera, which is effective in 
the treatment of cardiogenic shock and kidney failure [2]. Therefore, measurement of dopamine level in the human body is necessary.

Recently, in the realm of biomolecule detection such as dopamine, the electrochemical sensor has become one of the most essential detection technologies. It has small smart equipment and real-time monitoring. Moreover, immunoassays, biosensors, and other disciplines of research use the electrochemical sensors for various applications. Nowadays, metal oxide based on electrochemical sensors received huge attention towards dopamine detection [2]. Among the metal oxide, $\mathrm{CuO}$ semiconductors are excellent candidates for dopamine detection. Owing to their unique properties, such as electrocatalytic catalytic activity, antipoisoning of chloridion, and small band gap, they show a magnificent quality. For instance, Reddy coworkers reported that $\mathrm{CuO}$ nanoparticles have sensor characteristics for determining dopamine electrochemically [3]. Furthermore, Li et al. [4] reported Ag-doped $\mathrm{CuO}$ nanoparticles for the electrochemical determination of DA in human serum, Zhuang et al. [5] synthesized $\mathrm{Co}_{3} \mathrm{O}_{4} / \mathrm{CuO}$ nanocage for dopamine biosensing, and Zou et al. accounted for g-C3N4/CuO nanocomposites for the evaluation of dopamine [6].

Electrical, optical, heterogeneous catalysis, photovoltaic devices, FE emitters, gas sensing, Li ion electrode materials, and magnetic storage media have all been successfully made with copper oxide nanoparticles [7]. Though there are several attempts for preparing homogeneous nanoparticles and nanostructured metal oxides (NMOs) applied in the field of dopamine sensor, owing to their elevated oxidation potential, trivial sensitivity, and fouling of the oxidation signals, the researchers nowadays develop nanocomposite materials to resolve these problems [8].

A polymer-incorporated nanomaterial is frequently utilized to ameliorate the conductivity and catalytic tendency of sensors and to drastically increase the strength of the electrochemical transmission when developing nanocomposites based on metal oxide/copper oxide [9]. For instance, polymers such as PEG [10], PVP [11], PVA [12], PAA [13], and polyaniline (PANI) [14] are effectively used in the fabrication of a biosensor. The polymer plays a huge attention in electrochemical sensor because of the unique characters of polymer such as conductive nature, compatibility, electron supporter, and inexpensive $[15,16]$. As a result, dopamine levels have been linked to the sensitivity and advancement of neurological disorders such as Parkinson's and Alzheimer's diseases. The ability to detect DA in a sensitive and selective manner is critical for diagnosing neurological illnesses. To the best of our knowledge, no study has reported the synthesis of CuO-modified PVA nanocomposite for the detection of dopamine. In this study, a CuO/PVA-modified GCE-based electrochemical sensor was established for the detection of dopamine.

\section{Materials and Methods}

$2.4 \mathrm{~g}$ of $0.1 \mathrm{M}$ copper nitrate trihydrate was dissolved in $100 \mathrm{~mL}$ of distilled water (DW), and $0.8 \mathrm{~g}$ of $0.2 \mathrm{M} \mathrm{NaOH}$ was dissolved in $100 \mathrm{~mL}$ of DW separately. The copper

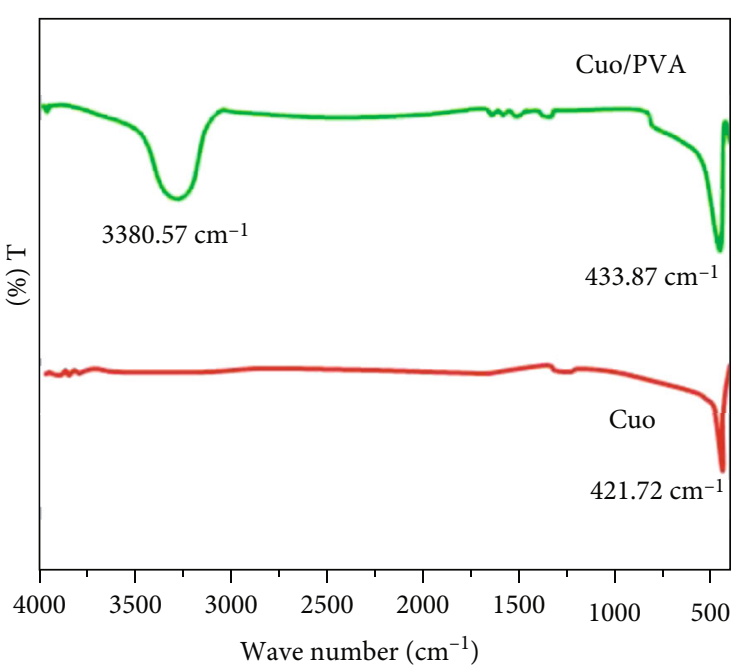

Figure 1: FT-IR spectrum of (a) $\mathrm{CuO}$ and (b) $\mathrm{CuO} / \mathrm{PVA}$ nanocomposites.

nitrate trihydrate solution was taken in a flask, and the $\mathrm{NaOH}$ solution was added dropwise under continuous magnetic stirring for $2 \mathrm{~h}$. The precipitate was then filtered off and heated in a hot air oven at $120^{\circ} \mathrm{C}$ for $1 \mathrm{hr}$. The product was finely crushed and calcinated at $500^{\circ} \mathrm{C}$ for $2 \mathrm{hrs}$ in a muffle furnace, and the obtained product was black in colour. Then, the PVA was incorporated on the $\mathrm{CuO}$ nanoparticles through the chemical impregnated method. The synthesized nanocomposite was characterized using FT-IR, XRD, SEM, and EDS. The prepared CuO/PVA nanocomposite was employed as a dopamine (DA) sensor.

\section{Result and Discussion}

3.1. FT-IR. The tentative frequency assignment of arranged spectra for pure and PVA-coated $\mathrm{CuO}$ nanoparticles is shown in Figure 1. The major characteristic peaks at $\sim 3380.57 \mathrm{~cm}^{-1}$ for O-H stretching mode of PVA [17]. There are sharp characteristic vibrational bands (Figures 1(a) and 1(b)) observed at 421.72 and $433.87 \mathrm{~cm}^{-1}$ in the spectrum of pure and PVA-incorporated $\mathrm{CuO}$ NPs which are corresponding towards the $\mathrm{Cu}-\mathrm{O}$ bond formation and vibrations of $\mathrm{CuO}$ monoclinic phase [18]. This affirmed the formation of $\mathrm{CuO}$ nanoparticle, and no impurity peaks was found in the sample as well.

3.2. Raman Analysis. Figure 2 visualizes the Raman spectrum of $\mathrm{CuO}, \mathrm{PVA}$-coated $\mathrm{CuO}$ NPs. In Figure 3(a), the Raman peaks observed at 291.71, 332.38, and $629.23 \mathrm{~cm}^{-1}$ are related to the $\mathrm{Ag}, \mathrm{B}_{\mathrm{g}}{ }^{1}$, and $\mathrm{B}_{\mathrm{g}}{ }^{2}$ mode of $\mathrm{CuO}$ [19]. Then, Raman bands are positioned at 300.54, 347.27, and $632.54 \mathrm{~cm}^{-1}$ in the PVA-modified CuO NPs (Figure 2(b)) sample. The intensity of the Raman peaks expanded in the PVA-incorporated $\mathrm{CuO}$ NPs renders to the $\mathrm{CuO}$ modified with PVA.

Moreover, the Raman bands located at 2948.63, and $3418.84 \mathrm{~cm}^{-1}$ are relevant to the elongated mode of C-C and $\mathrm{O}-\mathrm{H}$ in PVA $[20,21]$. This reveals the capping action 


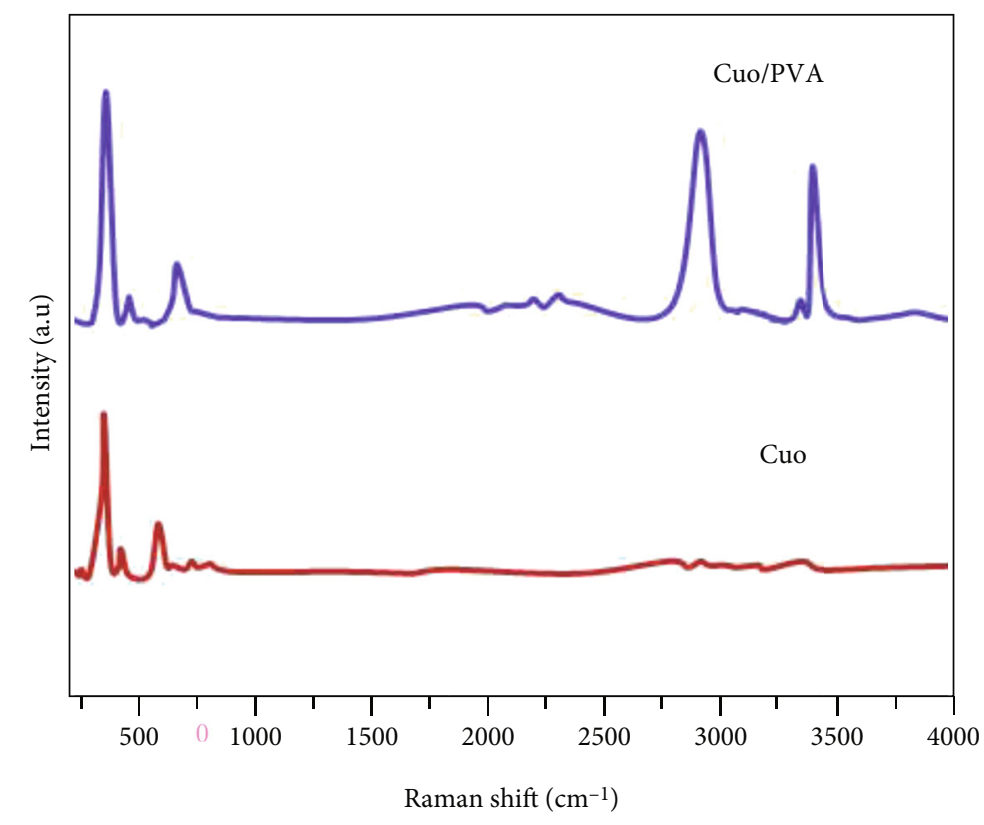

Figure 2: Raman spectrum of (a) $\mathrm{CuO}$ and (b) $\mathrm{CuO} / \mathrm{PVA}$ nanocomposites.

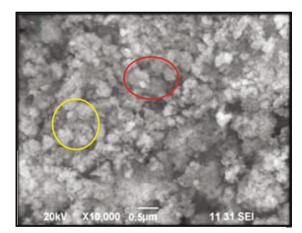

(a)

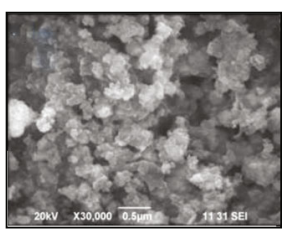

(b)
Figure 3: SEM images of (a) $\mathrm{CuO}$ and (b) $\mathrm{CuO} / \mathrm{PVA}$ nanocomposites.

of PVA on the $\mathrm{CuO}$ surface. Further, the Raman bands are red shifted in the Raman spectrum of PVA-coated $\mathrm{CuO}$ NPs showing the surface enhancement effect.

3.3. Crystal Structure. Figure 4 visualizes the XRD pattern of synthesized $\mathrm{CuO}$ and PVA-coated $\mathrm{CuO}$ NPs. The formation of $\mathrm{CuO}$ phase in $700^{\circ} \mathrm{C}$ annealed samples was confirmed by an X-ray diffractometer. The average crystallite sizes (D) were calculated by Scherrer's formula (eqution (1)) given below.

$$
D=\frac{K \lambda}{\beta \cos \theta},
$$

where $\lambda$ is the $\mathrm{X}$-ray wavelength, $\beta$ stands for FWHM, $K$ is equals to 0.89 , and $\theta$ is the Bragg diffraction angle. The average particle sizes of the nanoparticles were calculated to be 30.78 and $15.16 \mathrm{~nm}$ for $\mathrm{CuO}$ and PVA-coated $\mathrm{CuO}$, respectively. The diffraction peaks were matched using JCPDS software, and it was well-matched with the $\mathrm{CuO}$ of file no. JCPDF 895899 (Figure $4(\mathrm{a})$ ) acquired at $35.3^{\circ}, 38.5^{\circ}, 48.6^{\circ}, 58.1^{\circ}, 61.8^{\circ}$, $66.4^{\circ}$, and $68.5^{\circ}$ can be assigned to the (-111), (111), (-202), $(-113),(-311)$, and (220) planes of $\mathrm{CuO}[22]$ phase: monoclinic, lattice: end-centered, $(a=4.68, b=3.42$, and $c=5.13)$.
There are no debasement peaks in the patterns, indicating that the produced $\mathrm{CuO}$ samples are pure, and the crisp diffraction peaks reveal a magnificent crystal structure of the created $\mathrm{CuO}$. Moreover, the XRD pattern of $\mathrm{CuO}$ compared with PVA-incorporated CuO NPs (Figure 4(b)) can keep the typical $\mathrm{CuO}$ crystal structure afterward incorporating with PVA.

There is a trivial alteration in crystallite size while there is intercalation of PVA. This reduction of crystallite size is chiefly due to the alteration in the host $\mathrm{CuO}$ by the doping/capping agent. This reveals the incorporation of PVA on the surface of $\mathrm{CuO}$. Hence, construction of a nanocomposite is confirmed. The FT-IR and Raman results corroborate very well with the XRD result.

3.4. Morphological Study. Figure 3 visualizes the SEM images of $\mathrm{CuO}$ PVA-modified $\mathrm{CuO}$ NPs. The SEM image of $\mathrm{CuO}$ (Figure 3(a)) shows small rods/ball-like structure, and the surface is rough. However, PVA-coated $\mathrm{CuO}$ NPs (Figure 3(b)) exhibit small hallow nanoflake-like morphology, and the size of the PVA-coated CuO NPs is smaller than $\mathrm{CuO}$. This illustrates the doping/capping happening on the surface of $\mathrm{CuO}$. Consequently, the PVA dramatically change the cryogenically fractured surface of the PVAincorporated $\mathrm{CuO}$ NPs.

The elemental distributions of prepared nanomaterials were determined by EDS measurement. The EDS spectrum of $\mathrm{CuO}$ and PVA-coated $\mathrm{CuO}$ NPs was presented in Figures 5(a) and 5(b). The fundamental peaks of $\mathrm{Cu}$ and $\mathrm{O}$ are observed in the EDS spectrum. The uncoated sample exhibits the purity of the $\mathrm{CuO}$ nanoparticle. The fabricated nanomaterials display decent stoichiometry and profoundly porous nature. The sensor's very porous surface of PVAmodified $\mathrm{CuO}$ NPs is a key feature. Furthermore, the intensity of $\mathrm{Cu}$ increases from 1490.18 to 2487.72 in the EDS spectrum of PVA-coated $\mathrm{CuO}$ NPs (Figure 5(b)). This is 


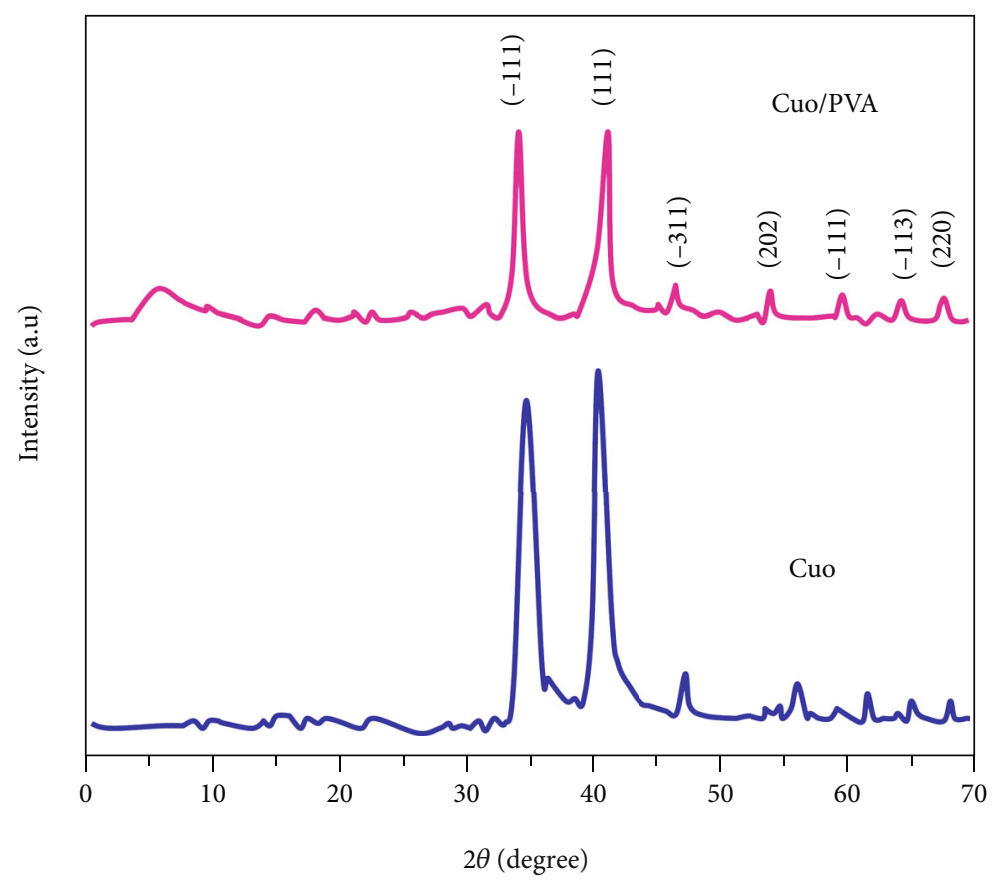

FIGURE 4: XRD patterns of (a) $\mathrm{CuO}$ and (b) $\mathrm{CuO} / \mathrm{PVA}$ nanocomposites.

because the surface modifier of PVP enlarges the intensity of the $\mathrm{Cu}$. It corroborates the PVA present on the surface of $\mathrm{CuO}$.

3.5. Application. The neurotransmitters are endogenous substances that allow nerve impulses to be transmitted between neurons via the synapse. It also relaxes the brain while stimulating excitatory neurotransmitters. In neurotransmitter progression, DA acts as a messenger molecule, binding to neurotransmitter receptors and transporters by magnitude of distribution between the synaptic fissures [23]. DA, on the other hand, is a rare neurotransmitter in that it is classified as both excitatory and inhibitory. It regulates attention, cognition, pleasure, movement, and hormonal functions, among other things. It is also found in the CNS, hormonal, urinary system, and heart-circulatory systems [24]. The quantity of dopamine that is abnormally formed in the CNS is a symptom of a fundamental neurological problem in the body of the person. As a result, DA monitoring takes precedence.

3.5.1. Study of Dopamine Sensing on a CuO/PVA-Modified GC Electrode. The electrocatalytic activity of $\mathrm{CuO} / \mathrm{GCE}$ and $\mathrm{CuO} / \mathrm{PVA} / \mathrm{GCE}$ nanocomposites was examined by cyclic voltammetry $(\mathrm{CV})$ studies in $1 \mathrm{mM}$ of $\mathrm{K}_{3}\left[\mathrm{Fe}(\mathrm{CN})_{6}\right]$, under $0.1 \mathrm{M}$ of PBS ( $\mathrm{pH}=7.0)$. Figure 6 shows couple of distinct redox peak seemed to bare GC electrode. This demonstrates that the redox behavior of DA may be accomplished using a two electrons and two protons method, which is possible since electrons transfer at the base GCE electrode in a quasireversible and sluggish manner. Several anodic and cathodic curves were seen at 0.23 and $-0.11 \mathrm{~V}$ for $\mathrm{CuO} / \mathrm{GCE}$, respectively, as well as a redox peak at 0.20 and $-0.14 \mathrm{~V}$ for $\mathrm{CuO} / \mathrm{PVA} / \mathrm{GCE}$. Among these modified elec- trodes, the anodic peak current of $\mathrm{CuO} / \mathrm{PVA} / \mathrm{GCE}$ has been increased. This shows the high surface area and promotes more conducting electron transfer from $\mathrm{K}_{3}\left[\mathrm{Fe}(\mathrm{CN})_{6}\right]$ to the $\mathrm{CuO} / \mathrm{PVA} / \mathrm{GC}$ electrode.

The higher anodic curve potential is due to the excellent electrooxidation of $\mathrm{Cu}$ (II)/Cu (III) towards DA. The redox behavior of $\mathrm{CuO} / \mathrm{PVA} / \mathrm{GCE}$ revealed the brilliant electrocatalytic activity and enormous surface area provided by PVA.

3.5.2. Amperometric Detection of Dopamine at CuO/PVAModified GC Electrode. The detection limit and concentration range are crucial factors to consider when evaluating the performance of an electrochemical sensor. CuO/PVA/ amperometric GCE's reaction to DA in $0.1 \mathrm{M}$ PB solution was measured. The potential anodic peak was observed in the range of +0.1 to $+0.3 \mathrm{~V}$ in Figure 7 . As a result, the best applied potential may be found between +0.1 and $+0.3 \mathrm{~V}$. The effect of applied potential on amperometric measurements was inspected by adding $2 \mu \mathrm{M}$ of dopamine every 50 seconds at varied potentials of $+0.1,+0.2$, and $+0.3 \mathrm{~V}$.

The current responsiveness of $2 \mu \mathrm{M}$ DA hiked dramatically as the applied potential was increased from +0.1 to $+0.3 \mathrm{~V}$, as shown in Figure 7. At $+0.2 \mathrm{~V}$, the current response was 1 -fold larger than that of $+0.1 \mathrm{~V}$ and 1-fold smaller than that of $+0.3 \mathrm{~V}$. As a result, the ideal constant applied potential for amperometric detection of DA was determined to be +0.2 V. $I_{\text {pa }}(A)=7.34+0.56 C_{\text {dopamine }}$ with correlation coefficient $\left(R^{2}\right) .0 .9914$ is calculated from the calibration plot (not shown) of the optimal applied potential at $+0.1 \mathrm{~V}$ with the linear regression formula. With a sensitivity of $183.12 \mu \mathrm{A} \mathrm{mM}^{-1}$ $\mathrm{cm}^{-2}$, the sensor has a small detection limit of $(S / N=3)$ of $0.017 \mu \mathrm{M}$.

Table 1 compares the results of the current DA sensor to those of other DA sensors that have been reported. $\mathrm{CuO}$ / 


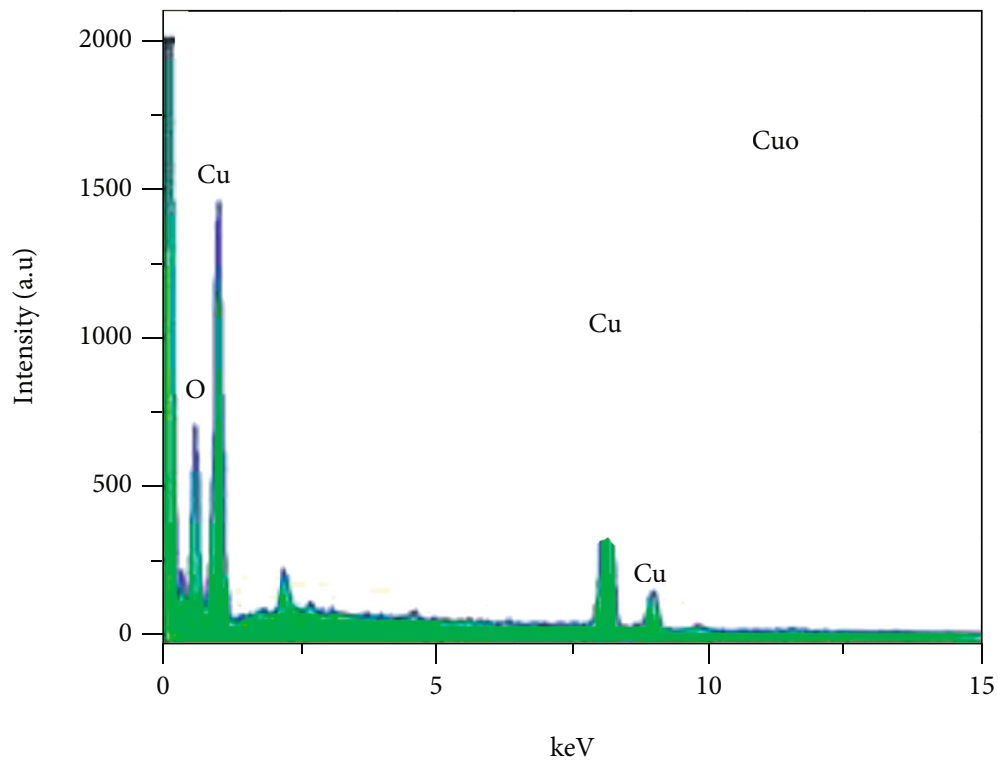

(a)

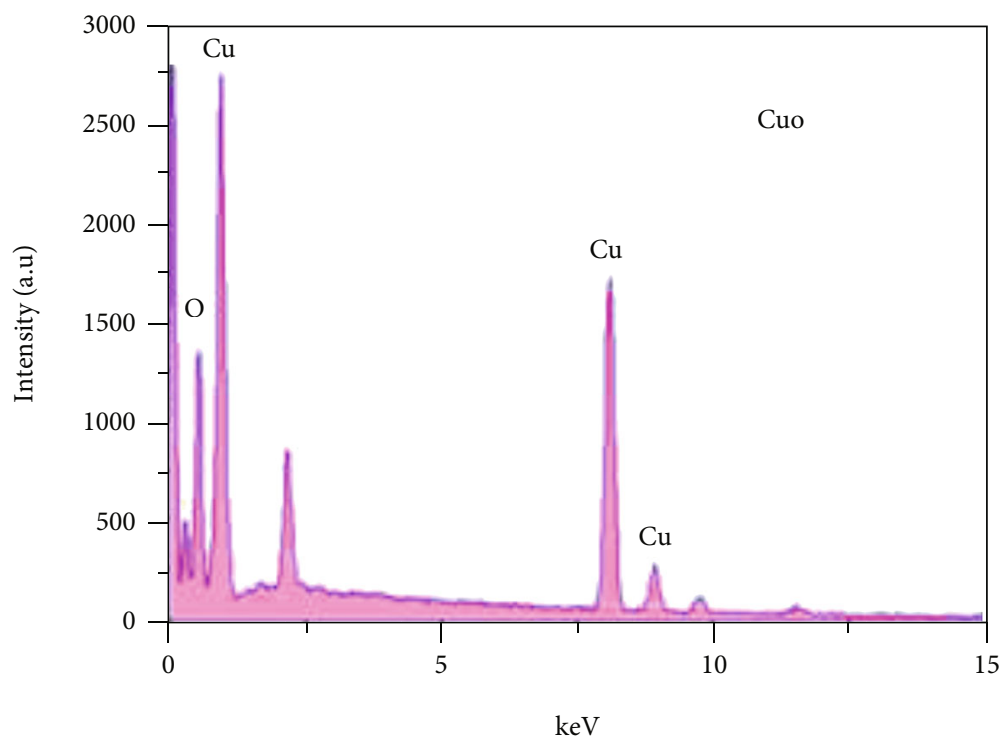

(b)

Figure 5: EDX images of (a) $\mathrm{CuO}$ and (b) $\mathrm{CuO} / \mathrm{PVA}$ nanocomposites.

PVA/GC electrode, among the many modified electrodes, offers greater sensitivity, an extensive linear range, a lower detection limit, and speedy detection of DA, making it a promising choice for the dopamine sensor.

3.5.3. Interference Analysis. To examine the selectivity of the sensor towards dopamine, an interference study was analyzed. The interference species such as $100 \mu \mathrm{M}$ of fructose, $100 \mu \mathrm{M}$ of sucrose, $100 \mu \mathrm{M}$ of lactose, $100 \mu \mathrm{M}$ of glucose, $100 \mu \mathrm{M}$ ureic acid (UA), $100 \mu \mathrm{M}$ of ascorbic acid (AA), $100 \mu \mathrm{M}$ of urea, and $100 \mu \mathrm{M}$ of hydrogen peroxide as well as the common ionic species such as potassium chloride in biological media were added to the electrolyte solution during the amperometric analysis of
DA. As shown in Figure 8, none of these species disclose any important manipulate on the DA oxidation current even at high concentration $(100 \mu \mathrm{M})$ indicates the stupendous selectivity of the $\mathrm{CuO} / \mathrm{PVA} / \mathrm{GC}$ electrode towards DA detection.

3.5.4. Stability and Reproducibility. The electrochemical sensor performance is primarily evaluated by the steadiness and reproducibility of the produced sensor. For $0.5 \mu \mathrm{M}$ of DA in $0.1 \mathrm{M}$ of PBS ( $\mathrm{pH}=7$ ), the CVs of the $\mathrm{CuO} / \mathrm{PVA} /$ GCE-modified electrode were recorded. For 20 repeated trials, the oxidation peak potential of DA stayed constant with a relative standard deviation of 1.3 percent and 1.1 percent, respectively. To test the modified electrodes' repeatability, 


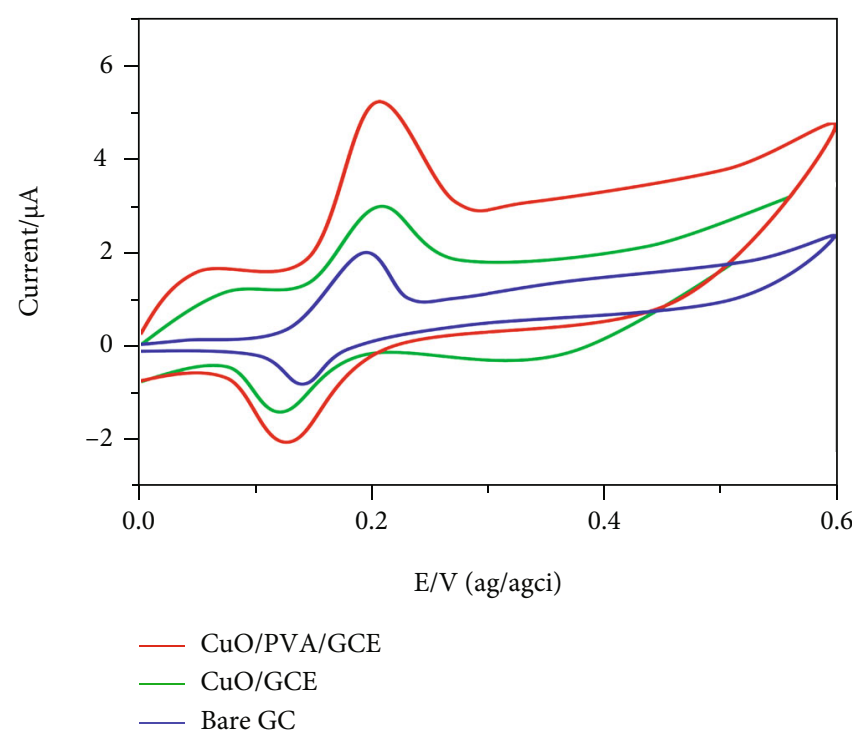

Figure 6: $\mathrm{CV}$ curve of $\mathrm{CuO} / \mathrm{GCE}$ and $\mathrm{CuO} / \mathrm{PVA} / \mathrm{GCE}$ in a $0.1 \mathrm{M} \mathrm{PB}$ solution at the scan rate of $50 \mathrm{mV} \mathrm{s}^{-1}$.

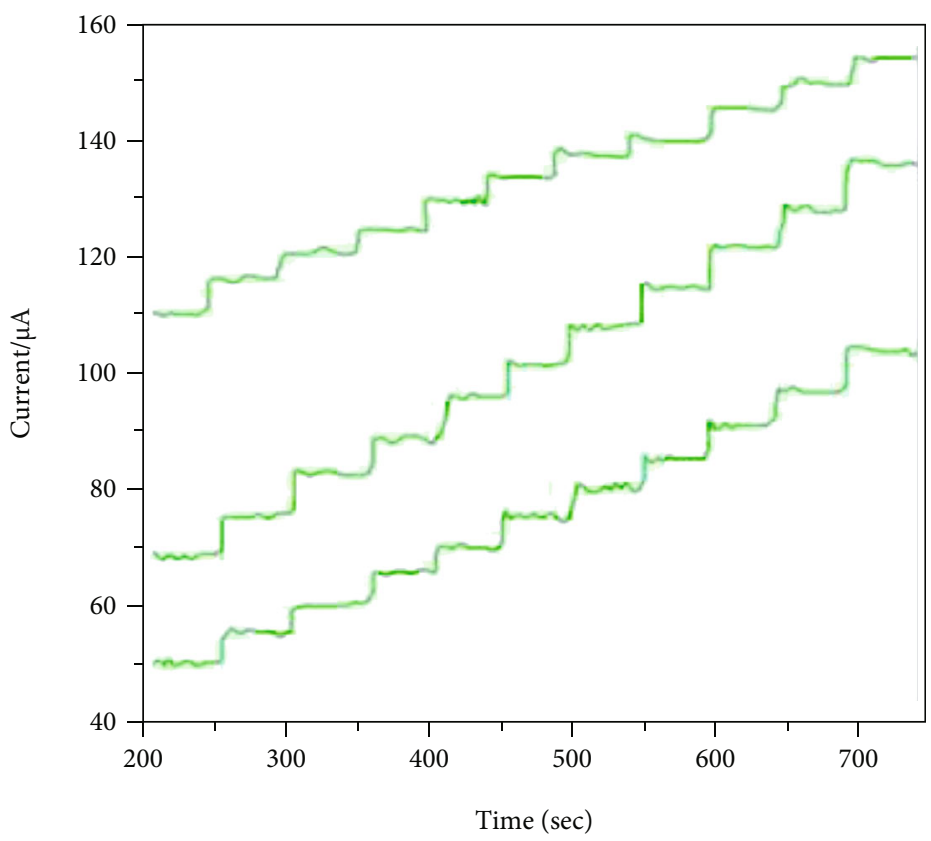

Figure 7: Amperometric measurement of CuO/PVA/GCE biosensor with the addition of each $2 \mu \mathrm{M}$ dopamine in $0.1 \mathrm{M}$ of PBS analyzed at $0.1,0.2$, and $+0.3 \mathrm{~V}$.

$10 \mathrm{CuO} / \mathrm{PVA} / \mathrm{GCE}$ sensors were fabricated identically for the monitoring of DA, and their electrocatalytic current signal was established with RSD of 5.09 percent. These findings show that the suggested modified electrode can function as a stable biosensor for DA with elevated sensitivity and selectivity.

3.6. Real Sample Analysis. The urine samples from the male patient were accumulated at the Tirunelveli Medical College Hospital, Tirunelveli. Primarily, the urine sample was diluted 10 times before using a medium for dopamine analysis. The DA was calculated by the SA method. The analytical outcomes are displayed in Table 2. All samples show a retrieval of more than $100 \%$, which may be due to the inherent dopamine present in biological samples or complex matrix effects of the medium. However, the recovery was noticed to be very close to $100 \%$; this discloses the appropriateness and selectivity of $\mathrm{CuO} / \mathrm{PVA} / \mathrm{GCE}$ sensors for the discovery of DA in biological samples. 
TABle 1: Assessment of sensing action of the CuO/PVA/GC electrode with other fabricated electrodes.

\begin{tabular}{|c|c|c|c|}
\hline S. no & Electrodes & $\begin{array}{l}\text { LOD } \\
(\mu \mathrm{M})\end{array}$ & Reference \\
\hline 1 & $\mathrm{Au} / \mathrm{Pt} / \mathrm{GCE}$ & 24 & {$[25]$} \\
\hline 2 & $\mathrm{Pd}_{3} \mathrm{Pt}_{1} / \mathrm{RGO} / \mathrm{GCE}$ & 0.04 & {$[26]$} \\
\hline 3 & Ag NPs/P (Arg)-GO/GCE & 0.01 & [27] \\
\hline 4 & Ni- ZIF-8/N S-CNTs/GCE & 0.93 & {$[28]$} \\
\hline 5 & Pd NPs/GR/CS/GCE & 0.1 & [29] \\
\hline 6 & $\mathrm{PdAg} \mathrm{NFs} / \mathrm{rGO} / \mathrm{GCE}$ & 0.048 & {$[30]$} \\
\hline 7 & Ni-meso-PANI/GCE & 9.6 & {$[31]$} \\
\hline 8 & $\mathrm{Ni} / \mathrm{C} / \mathrm{GCE}$ & 0.05 & {$[32]$} \\
\hline 9 & GP-MWCNTs-Au NCs/GCE & 0.77 & {$[33]$} \\
\hline 10 & $\mathrm{CuO} / \mathrm{PVA} / \mathrm{GCE}$ & 0.017 & This work \\
\hline
\end{tabular}

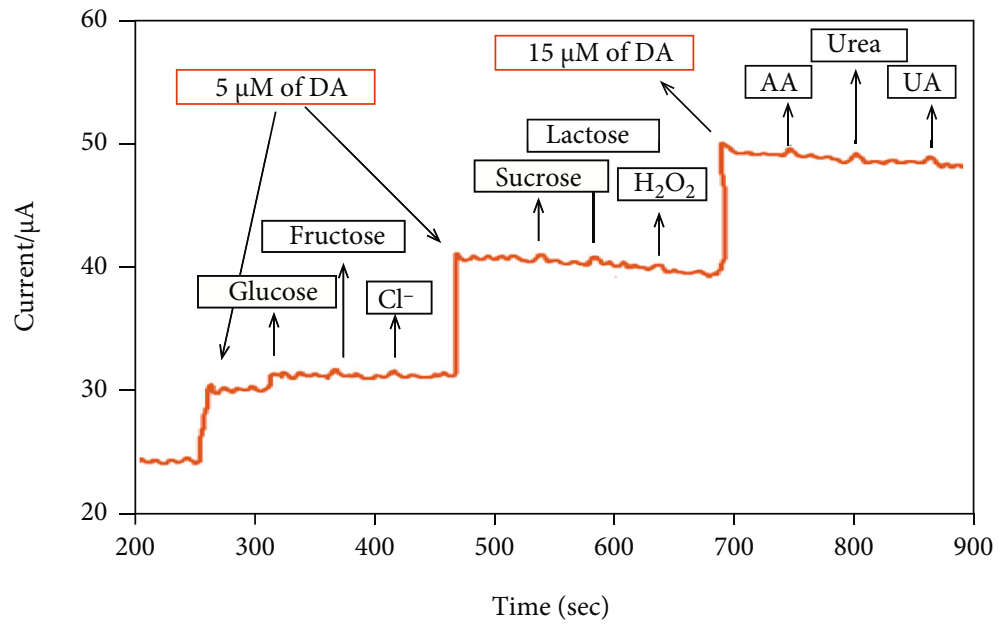

FIgURE 8: Amperometric detection of interfering species of the sensor in $0.1 \mathrm{M}$ PBS with $100 \mu \mathrm{M}$ of fructose, $100 \mu \mathrm{M}$ of glucose, $100 \mu \mathrm{M}$ of lactose, $100 \mu \mathrm{M}$ of sucrose, $100 \mu \mathrm{M}$ ureic acid (UA), $100 \mu \mathrm{M}$ of ascorbic acid (AA), $100 \mu \mathrm{M}$ of urea, and $100 \mu \mathrm{M}$ of hydrogen peroxide as well as the common ionic species potassium chloride.

TABLE 2: Determination of DA in human urine samples using the $\mathrm{CuO} / \mathrm{PVA} / \mathrm{GCE}$ sensor (practical application of the proposed method $n=3)$.

\begin{tabular}{lcccc}
\hline $\begin{array}{l}\text { Urine } \\
\text { sample }\end{array}$ & $\begin{array}{c}\text { Added } \\
(\mu \mathrm{M})\end{array}$ & $\begin{array}{c}\text { Found } \\
(\mu \mathrm{M})\end{array}$ & $\begin{array}{c}\text { RSD } \\
(\%)\end{array}$ & $\begin{array}{c}\text { Recovery } \\
(\%)\end{array}$ \\
\hline $\mathrm{A}$ & 5 & 4.13 & 2.69 & 98.50 \\
$\mathrm{~B}$ & 5 & 4.54 & 2.45 & 98.89 \\
$\mathrm{C}$ & 5 & 4.13 & 2.39 & 98.79 \\
$\mathrm{D}$ & 5 & 4.49 & 1.94 & 99.43 \\
$\mathrm{E}$ & 5 & 4.67 & 2.23 & 99.63 \\
\hline
\end{tabular}

\section{Conclusion}

We were able to successfully produce copper oxide using a simple chemical precipitation process and a surface modification of PVA (wt\%). By using a simple chemical precipitation procedure, the $\mathrm{p}$-XRD analysis verified that the sample generated with and without PVA had a monoclinic arrangement. The production of nanoballs/nanorods can be seen in morphological studies of the produced nanocomposite. The presence of copper and oxygen was validated by EDX. $\mathrm{CuO} / \mathrm{PVA} / \mathrm{GCE}$ has been created as a biosensing material. The performance of PVA, which serves as a medium for electron transport among the modified electrode and dopamine, increases the electrocatalytic activity of $\mathrm{CuO}$. For dopamine determination, the suggested and produced structural compound $\mathrm{CuO} / \mathrm{PVA} / \mathrm{GCE}$ demonstrated great electrochemical stability, excellent selectivity, increased sensitivity $\left(183.12 \mu \mathrm{AmM}^{-1} \mathrm{~cm}^{-2}\right)$, and a lower detection limit of $0.017 \mu \mathrm{M}(S / N=3)$. This information is applicable to the examination of human real-life samples as well.

\section{Data Availability}

The data used to support the findings of this study are included within the article. 


\section{Conflicts of Interest}

The authors declare no conflict of interest.

\section{Acknowledgments}

Princess Nourah bint Abdulrahman University Researchers Supporting Project number (PNURSP2022R26), Princess Nourah bint Abdulrahman University, Riyadh, Saudi Arabia.

\section{References}

[1] A. Manbohi and S. H. Ahamadi, "Sensitive and selective detection of dopamine using electrochemical microfluidic paper based analytical nanosensor," Sensing and Bio-Sensing Research, vol. 23, p. 100270, 2019.

[2] C. Zhang, Z. Cao, G. Zhang et al., "An electrochemical sensor based on plasma-treated zinc oxide nanoflowers for the simultaneous detection of dopamine and diclofenac sodium," Microchemical Journal, vol. 158, 2020.

[3] S. Reddy, B. E. K. Swamy, and H. Jayadevappa, "CuO nanoparticle sensor for the electrochemical determination of dopamine," Electrochimica Acta, vol. 61, pp. 78-86, 2012.

[4] Y. Y. Li, P. Kang, S. Q. Wang, Z. G. Liu, Y. X. Li, and Z. Guo, "Ag nanoparticles anchored onto porous $\mathrm{CuO}$ nanobelts for the ultrasensitive electrochemical detection of dopamine in human serum," Sensors and Actuators B: Chemical, vol. 327, p. $128878,2021$.

[5] Y. Zhuang, X. Zhang, Q. Chen, S. Li, H. Cao, and Y. Huang, " $\mathrm{Co}_{3} \mathrm{O}_{4} / \mathrm{CuO}$ hollow nanocage hybrids with high oxidase-like activity for biosensing of dopamine," Materials Science and Engineering: C, vol. 94, pp. 858-866, 2019.

[6] J. Zou, S. Wu, Y. Liu et al., "An ultrasensitive electrochemical sensor based on $2 \mathrm{D} \mathrm{g}-\mathrm{C}_{3} \mathrm{~N}_{4} / \mathrm{CuO}$ nanocomposites for dopamine detection," Carbon, vol. 130, pp. 652-663, 2018.

[7] T. Wen, W. Zhu, C. Xue et al., "Novel electrochemical sensing platform based on magnetic field-induced self- assembly of $\mathrm{Fe}_{3} \mathrm{O}_{4} @$ Polyaniline nanoparticles for clinical detection of creatinine," Biosensors \& Bioelectronics, vol. 56, pp. 180-185, 2014.

[8] A. M. Azharudeen, T. Suriyakala, M. Rajarajan, and A. Suganthi, "An improved sensitive and selective nonenzymatic dopamine biosensor based on PEG assisted $\mathrm{CuO}$ nanocomposites," Egyptian Journal of Chemistry, vol. 62, pp. 487-500, 2019.

[9] B. Li, Y. Zhou, W. Wu et al., "Highly selective and sensitive determination of dopamine by the novel molecularly imprinted poly(nicotinamide)/CuO nanoparticles modified electrode," Biosensors \& Bioelectronics, vol. 67, pp. 121-128, 2015.

[10] N. Kohler, C. Sun, A. Fichtenholtz, J. Gunn, C. Fang, and M. Q. Zhang, "Methotrexate-immobilized poly (ethylene glycol) magnetic nanoparticles for MR imaging and drug delivery," Small, vol. 2, no. 6, pp. 785-792, 2006.

[11] H. Y. Lee, S. H. Lee, C. Xu et al., "Synthesis and characterization of PVP-coated large core iron oxide nanoparticles as an MRI contrast agent," Nanotechnology, vol. 19, 2008.

[12] R. Hariharan, S. Senthilkumar, A. Suganthi, and M. Rajarajan, "Photodynamic action of curcumin derived polymer modified ZnO nanocomposites," Materials Research Bulletin, vol. 94, pp. 454-459, 2005.
[13] X. Mo, C. Y. Wang, M. You, Y. R. Zhu, Z. Y. Chen, and Y. Hu, "A novel ultraviolet-irradiation route to CdS nanocrystallites with different morphologies," Materials Research Bulletin, vol. 36, no. 13-14, pp. 2277-2282, 2001.

[14] A. M. Azharudeen, R. Karthiga, M. Rajarajan, and A. Suganthi, "Fabrication, characterization of polyaniline intercalated $\mathrm{NiO}$ nanocomposites and application in the development of nonenzymatic glucose biosensor," Arabian Journal of Chemistry, vol. 13, no. 2, pp. 4053-4064, 2020.

[15] O. Rezaee, H. M. Chenari, F. E. Ghodsi, and H. Ziyadi, "Preparation of PVA nanofibers containing tungsten oxide nanoparticle by electrospinning and consideration of their structural properties and photocatalytic activity," Journal of Alloys and Compounds, vol. 690, pp. 864872, 2017.

[16] T. Jan, J. Iqbal, V. Farooq et al., "Structural, Raman and optical characteristics of $\mathrm{Sn}$ doped $\mathrm{CuO}$ nanostructures: a novel anticancer agent," Ceramics International, vol. 41, no. 10, pp. 13074-13079, 2015.

[17] F. Bayansal, O. Sachin, and H. W. Cetikare, "Mechanical and structural properties of $\mathrm{Li}$-doped $\mathrm{CuO}$ thin films deposited by the successive ionic layer adsorption and reaction method," Thin Solid Films, vol. 697, p. 137839, 2020.

[18] Y. F. Zhang, M. M. Guo, Y. Zhang et al., "Flexible, stretchable and conductive PVA/PEDOT: PSS composite hydrogels prepared by SPIN strategy," Polymer Testing, vol. 81, 2020.

[19] H. Zhang and J. Zhang, "The preparation of novel polyvinyl alcohol (PVA)-based nanoparticle/carbon nanotube (PNP/ CNTs) aerogel for solvents adsoption application," Journal of Colloid and Interface Science, vol. 569, pp. 264-266, 2020.

[20] M. Sun, Y. Lei, H. Cheng et al., "Mg doped $\mathrm{CuO}-\mathrm{Fe}_{2} \mathrm{O}_{3}$ composites activated by persulfate as highly active heterogeneous catalysts for the degradation of organic pollutants," Journal of Alloys and Compounds, vol. 825, p. 154036, 2020.

[21] M. A. Kurian, P. Gissen, M. Smith, S. J. Heales, and P. T. Clayton, "The monoamine neurotransmitter disorders an expanding range of neurological syndromes," The Lancet Neurology, vol. 10, no. 8, pp. 721-733, 2011.

[22] S. S. Castro, R. J. Mortimer, M. F. De Oliveira, and N. R. Stradiotto, "Electrooxidation and determination of dopamine using a Nafion ${ }^{\circledR}$-cobalt hexacyanoferrate film modified electrode," Sensor, vol. 8, no. 3, pp. 1950-1959, 2008.

[23] M. M. Ardakani, H. Rajabi, H. Beitollahi, B. Mirjalili, A. Akbari, and N. Taghavinia, "Voltammetric determination of dopamine at the surface of $\mathrm{TiO}_{2}$ nanoparticles modified carbon paste electrode," International Journal of Electrochemical Science, vol. 5, pp. 147-157, 2010.

[24] A. Galvan and T. Wichmann, "Pathophysiology of parkinsonism," Clinical Neurophysiology, vol. 119, no. 7, pp. 1459-1474, 2008.

[25] S. Thiagarajan and S. Chen, "Preparation and characterization of PtAu hybrid film modified electrodes and their use in simultaneous determination of dopamine, ascorbic acid and uric acid," Talanta, vol. 74, no. 2, pp. 212-222, 2007.

[26] J. Yan, S. Liu, Z. Zhang et al., "Simultaneous electrochemical detection of ascorbic acid, dopamine and uric acid based on graphene anchored with Pd-Pt nanoparticles," Colloids and Surfaces B: Biointerfaces, vol. 111, pp. 392-397, 2013.

[27] G. Tı̆̆, "Development of electrochemical sensor for detection of ascorbic acid, dopamine, uric acid and L-tryptophan based on ag nanoparticles and poly(l-arginine)-graphene oxide 
composite," Journal of Electroanalytical Chemistry, vol. 807, pp. 19-28, 2017.

[28] W. Yao, H. Guo, H. Liu et al., "High electrochemical performance of Ni-ZIF-8/N S-CNTs/CS composite for simultaneous determination of dopamine, uric acid and L-tryptophan," Microchemical Journal, vol. 152, p. 1043357, 2020.

[29] X. Wang, M. Wu, W. Tang et al., "Simultaneous electrochemical determination of ascorbic acid, dopamine and uric acid using a palladium nanoparticle/graphene/chitosan modified electrode," Journal of Electroanalytical Chemistry, vol. 695, pp. 10-16, 2013.

[30] L. X. Chen, J. N. Zheng, A. J. Wang, L. J. Wu, J. R. Chen, and J. J. Feng, "Facile synthesis of porous bimetallic alloyed PdAg nanoflowers supported on reduced graphene oxide for simultaneous detection of ascorbic acid, dopamine, and uric acid," Analyst, vol. 140, no. 9, pp. 3183-3192, 2015.

[31] M. U. A. Prathap and R. Srivastava, "Tailoring properties of polyaniline for simultaneous determination of a quaternary mixture of ascorbic acid, dopamine, uric acid, and tryptophan," Sensors and Actuators B: Chemical, vol. 177, pp. 239250, 2013.

[32] W. He, Y. Ding, W. Zhang, L. Ji, X. Zhang, and F. Yang, "A highly sensitive sensor for simultaneous determination of ascorbic acid, dopamine and uric acid based on ultra-small Ni nanoparticles," Journal of Electroanalytical Chemistry, vol. 775, pp. 205-211, 2016.

[33] X. Liu, S. Wei, S. Chen, D. Yuan, and W. Zhang, "Graphene-multiwall carbon nanotube gold nanocluster composites modified electrode for the simultaneous determination of ascorbic acid, dopamine, and uric acid," Applied Biochemistry and Biotechnology, vol. 173, no. 7, pp. 1717-1726, 2014. 